\title{
Erratum to: Optimal remifentanil dose for laryngeal mask airway insertion when co-administered with a single standard dose of propofol
}

\author{
Lionel Bouvet, MD • Xavier Da-Col, MD • \\ Thomas Rimmelé, MD • Bernard Allaouchiche, MD, PhD • \\ Dominique Chassard, MD, PhD · Emmanuel Boselli, MD, PhD
}

Published online: 8 May 2010

(C) Canadian Anesthesiologists' Society 2010

\section{Erratum to: Can J Anesth/J Can Anesth \\ DOI 10.1007/s12630-009-9249-9}

In the article entitled "Optimal remifentanil dose for laryngeal mask airway insertion when co-administered with a single standard dose of propofol" (Can J Anesth 2010; 57: 222-9) the laryngeal mask airway used in the study was the AuraOnce $^{\mathrm{TM}}$ supraglottic airway (Ambu Inc; Denmark). Reference is made to this device in the article.

The article inadvertently used the proprietary trade mark, LMA, to refer to the Ambu laryngeal masks. Being a proprietary trade mark of The Laryngeal Mask Company Limited, LMA is not freely available for use by third parties, either generically or as an abbreviation of "laryngeal mask airway". We appreciate that the only laryngeal mask to which the term LMA can correctly be applied is one that is manufactured by The Laryngeal Mask Company under the trade mark LMA. The Laryngeal Mask Company manufactured the first laryngeal mask - the $\mathbf{L M A}{ }^{\mathbf{T M}}$ airway - back in the late 1980s, and the trade mark has been proprietary to the Company since that time. We also appreciate that although other companies now manufacture laryngeal masks, the mark LMA remains proprietary to The Laryngeal Mask Company, and cannot be used as a generic descriptor of laryngeal mask airways made by other companies. The publisher apologizes for the error presented in the manuscript (Can J Anesth 2010; 57: 222-9).

The online version of the original article can be found under doi:10.1007/s12630-009-9249-9.

L. Bouvet, MD ( $($ ) $\cdot$ T. Rimmelé, MD .

B. Allaouchiche, $\mathrm{MD}, \mathrm{PhD}$ - E. Boselli, $\mathrm{MD}, \mathrm{PhD}$

Department of Anesthesia and Intensive Care, Edouard Herriot

Hospital, Hospices Civils de Lyon, 5 place d'Arsonval,

Lyon, France

e-mail: lionel.bouvet@chu-lyon.fr

L. Bouvet, MD · T. Rimmelé, MD .

B. Allaouchiche, MD, PhD - E. Boselli, MD, PhD

University of Lyon, Lyon 69003, France

X. Da-Col, MD - D. Chassard, MD, PhD

Femme-Mère-Enfant Hospital, Hospices Civils de Lyon,

The University of Lyon, Lyon, France 